\title{
Cannabidiol: brief compilation over a versatile molecule
}

\author{
Canabidiol: breve compilação sobre uma molécula versátil
}

Cannabidiol: breve recopilación sobre una molécula versátil

Received: 10/25/2021 | Reviewed: 11/04/2021 | Accept: 11/05/2021| Published: 11/09/2021

Caico Bruno Curcio Oliva de Paula

ORCID: https://orcid.org/0000-0003-0654-3594

Universidade Santo Amaro, Brazil

E-mail: curciopaula@icloud.com

Enzo Andrade Baldacci

ORCID: https://orcid.org/0000-0003-2302-7209

Universidade Santo Amaro, Brazil

E-mail: enzobaldacci4@gmail.com

Lucas Chen Cheng

ORCID: https://orcid.org/0000-0003-0051-5322

Universidade Santo Amaro, Brazil

E-mail: lucaschen98@hotmail.com

Mateus Bulbow Gozzi

ORCID: https://orcid.org/0000-0003-2662-2644 Universidade Santo Amaro, Brazil

E-mail: mbgozzi@gmail.com

Pedro Torquato Shibuya

ORCID: https://orcid.org/0000-0002-0594-9309

Universidade Santo Amaro, Brazil

E-mail: pedrotshibuya@gmail.com

Lucas Antonio Duarte Nicolau

ORCID: https://orcid.org/0000-0002-9904-2168

Universidade Federal do Delta do Parnaíba, Brazil

E-mail: lucasnicolau5@gmail.com

Jand Venes Rolim Medeiros

ORCID: https://orcid.org/0000-0002-7234-3382

Universidade Federal do Delta do Parnaíba, Brazil

E-mail: jandvebes@ufpi.edu.br

Renato Anghinah

ORCID: https://orcid.org/0000-0001-8414-8536

Universidade de São Paulo, Brazil

E-mail: anghinah@terra.com.br

Juliane Vismari de Oliveira

ORCID: https://orcid.org/0000-0001-5514-2397

Instituto de Assistência Médica ao Servidor Público Estadual, Brazil

Centro Universitário FMABC, Brazil

E-mail: julianevismari@ hotmail.com

Flávia de Sousa Gehrke

ORCID: https://orcid.org/0000-0002-2230-8853 Centro Universitário FMABC, Brazil

Instituto de Assistência Médica ao Servidor Público Estadual, Brazil

E-mail: flavia.gehrke@fmabc.com

Francisco Sandro Menezes-Rodrigues

ORCID: https://orcid.org/0000-0001-7913-0585

Universidade Federal de São Paulo, Brazil

E-mail: sandromrodrigues@ hotmail.com

\begin{abstract}
Cannabis sativa has been applied for medicinal purposes for thousands of years. Cannabidiol is the main nonpsychotropic compound in Cannabis sativa, and has its therapeutic effect extremely linked to the central nervous system, presenting pharmacological properties with great potential for the treatment of several pathologies. The aim is to identify and relate the therapeutic effects of cannabidiol in medicine, focusing on its therapeutic potential in epilepsy, autism, Parkinson's disease, Alzheimer's disease, oncological diseases, and chronic pain. In addition to presenting a brief history of cannabidiol and its chemical and pharmacological properties acting on the Central Nervous System. Integrative literature review, where articles were reviewed in Portuguese and English, based on PubMed, Scielo and Public Agencies. In 1960, the chemical structures of the main components of cannabis were identified, characterizing cannabidiol as a cannabinoid, which binds to cannabinoid receptors throughout the human
\end{abstract}


body, known as CB1 and CB2. The endocannabinoid system, described in 1990, further demonstrated the therapeutic properties of cannabidiol, elucidating its neuroprotective, antiepileptic, anxiolytic, antipsychotic, anti- inflammatory, anti-tumor, antioxidant, and anticonvulsant properties. Cannabinoids may, in the future, be an important therapeutic option in the treatment of Parkinson's and Alzheimer's diseases, epilepsy, autism, neoplasms and still acting in the relief of pain. This is due to the absence of psychoactive effects and cognition, safety, good tolerability, clinical trials with positive results and the wide spectrum of pharmacological actions.

Keywords: Cannabidiol; Therapeutic use; Cannabis; Central Nervous System.

\section{Resumo}

A Cannabis sativa tem sido aplicada para fins medicinais há milhares de anos. O canabidiol é o principal composto não psicotrópico da Cannabis sativa, e tem seu efeito terapêutico extremamente ligado ao sistema nervoso central, apresentando propriedades farmacológicas com grande potencial para o tratamento de diversas patologias. O objetivo é identificar e relacionar os efeitos terapêuticos do canabidiol na medicina, com foco em seu potencial terapêutico na epilepsia, autismo, doença de Parkinson, doença de Alzheimer, doenças oncológicas e dores crônicas. Além de apresentar um breve histórico do canabidiol e de suas propriedades químicas e farmacológicas atuando no Sistema Nervoso Central. Revisão integrativa da literatura, onde os artigos foram revisados em português e inglês, com base no PubMed, Scielo e Agências Públicas. Em 1960, foram identificadas as estruturas químicas dos principais componentes da cannabis, caracterizando o canabidiol como um canabinoide, que se liga a receptores canabinoides em todo o corpo humano, conhecidos como CB1 e CB2. O sistema endocanabinoide, descrito em 1990, demonstrou ainda as propriedades terapêuticas do canabidiol, elucidando suas propriedades neuroprotetoras, antiepilépticas, ansiolíticas, antipsicóticas, antiinflamatórias, antitumorais, antioxidantes e anticonvulsivantes. Os canabinóides podem, no futuro, ser uma importante opção terapêutica no tratamento das doenças de Parkinson e Alzheimer, epilepsia, autismo, neoplasias e ainda atuando no alívio da dor. Isso se deve à ausência de efeitos psicoativos e cognição, segurança, boa tolerabilidade, ensaios clínicos com resultados positivos e amplo espectro de ações farmacológicas.

Palavras-chave: Canabidiol; Uso terapêutico; Cannabis; Sistema Nervoso Central.

\section{Resumen}

El Cannabis sativa se ha aplicado con fines medicinales durante miles de años. El cannabidiol es el principal compuesto no psicotrópico de Cannabis sativa, y su efecto terapéutico está sumamente ligado al sistema nervioso central, presentando propiedades farmacológicas con gran potencial para el tratamiento de diversas patologías. El objetivo es identificar y relacionar los efectos terapéuticos del cannabidiol en la medicina, centrándose en su potencial terapéutico en epilepsia, autismo, enfermedad de Parkinson, enfermedad de Alzheimer, enfermedades oncológicas y dolor crónico. Además de presentar una breve historia del cannabidiol y sus propiedades químicas y farmacológicas actuando sobre el Sistema Nervioso Central. Revisión de literatura integradora, donde se revisaron artículos en portugués e inglés, con base en PubMed, Scielo y Agencias Públicas. En 1960, se identificaron las estructuras químicas de los principales componentes del cannabis, caracterizando al cannabidiol como un cannabinoide, que se une a los receptores de cannabinoides en todo el cuerpo humano, conocidos como CB1 y CB2. El sistema endocannabinoide, descrito en 1990, demostró además las propiedades terapéuticas del cannabidiol, dilucidando sus propiedades neuroprotectoras, antiepilépticas, ansiolíticas, antipsicóticas, antiinflamatorias, antitumorales, antioxidantes y anticonvulsivas. Los cannabinoides pueden, en el futuro, ser una opción terapéutica importante en el tratamiento de las enfermedades de Parkinson y Alzheimer, epilepsia, autismo, neoplasias y aún actuando en el alivio del dolor. Esto se debe a la ausencia de efectos psicoactivos y cognitivos, seguridad, buena tolerabilidad, ensayos clínicos con resultados positivos y el amplio espectro de acciones farmacológicas.

Palabras clave: Cannabidiol; Uso terapêutico; Cannabis; Sistema Nervioso Central.

\section{Introduction}

The plant Cannabis sativa comes being applied for medicinal purposes for thousands of years. Indications of the use of the plant in China date from 2700 A.C. for the treatment of various medical conditions such as constipation, pain, malaria, expectoration, epilepsy, tuberculosis, among others (Matos et al., 2017). In India, there are records of the use of the plant for relieving psychiatric symptoms since before 1000 B.C., administered like hypnotic and anxiolytic in the treatment of anxiety, mania and hysteria (Matos et al., 2017; Crippa et al., 2010). At the beginning of the $20^{\text {th }}$ century, extracts Cannabis were commercialized in England, Germany and the United States, for the treatment of mental disorders, especially as hypnotics and sedatives. In the 1960s, the chemical structures of the main components of cannabis were identified, characterizing cannabidiol (CBD) as a cannabinoid, as well as THC, which binds to cannabinoid receptors throughout the human body, known as CB 1 e 
CB2 (Matos et al., 2017; de Faria et al, 2020).

In the early 1990s, the endocannabinoid system was described and the pharmacological properties of cannabidiol became even more evident, elucidating its neuroprotective, antiepileptic, anxiolytic, antipsychotic, anti-inflammatory, antitumor, antioxidant and anticonvulsant properties (Matos et al., 2017; Santos et al., 2019; Gontijo et al., 2016).

CBD is the main non-psychotropic compound in Cannabis sativa, and has its therapeutic effect extremely linked to the central nervous system, presenting pharmacological properties with great potential for the treatment of several pathologies, such as epilepsy, autism, Parkinson's disease and Alzheimer's disease, in addition to the antineoplastic potential and in the relief of chronic pain (Matos et al., 2017; Crippa et al., 2010; Gontijo et al., 2016).

In the last decades, CBD has become the target of several experimental studies, in order to elucidate the uncertainties regarding the appearance of complications of different natures, as well as adverse effects not yet reported or unexpected allergic reactions, in order to designate a greater clinical applicability for the substance and its therapeutic potential (Matos et al., 2017; Gontijo et al., 2016).

The present literature review aims to identify and relate the therapeutic effects of CBD in medicine, focusing on its therapeutic potential in epilepsy, autism, Parkinson's disease, Alzheimer's disease, oncological diseases and pain chronic. In addition to presenting a brief history of cannabidiol and its chemical and pharmacological properties acting on the Central Nervous System (CNS).

\section{Methodology}

This is an integrative literature review. Articles in Portuguese or English and free full-text were reviewed, with scientific basis: PubMed, Scielo and Public Bodies. In addition, the following descriptors were used: "CBD and its therapeutic effects", "CBD and epilepsy", "CBD”, "CBD in the treatment of autism", "CBD and its neuroprotective effects", "CBD in the treatment of Parkinson", "Cannabidiol”, "CBD and Alzheimer's Disease”.

\section{Results}

The research resulted in 29 articles that were read and analyzed. Of these, 09 were discarded according to the selection criteria: repeated articles, without free full text or out of topic. Therefore, 20 articles were selected, Figure 1.

Figure 1. Flowchart of selected articles.

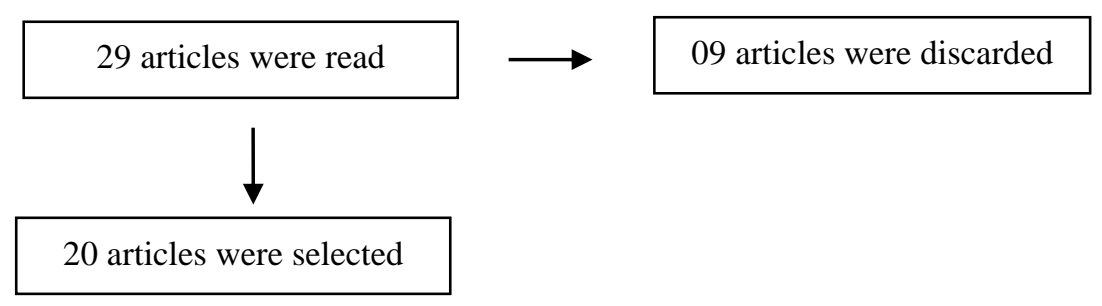

Source: Own authorship.

\section{Discussion}

\section{Cannabidiol (CBD)}

Cannabis consists of a shrub originating in Asia, belonging to the family of Cannabaceaes, whose species best known are Cannabis sativa and Cannabis indica, which are distinguished mainly by the growth mode, morphological characteristics 
and quantity of active ingredients. However, the predominant species in Brazil is Cannabis sativa, as it has better development in temperate and tropical climates. Known as "hashish", marijuana resin contains approximately 400 chemical compounds, including cannabinoids, components responsible for the psychoactive and pharmacological effects of the plant (Matos et al., 2017).

The main cannabinoids are the delta novel tetrahydrocannabinol ( $\Delta^{9}$-THC), a psychoactive cannabinoid, and CBD, a non-psychoactive cannabinoid (Matos et al., 2017; Gontijo et al., 2016; Pereira et al., 2018). These two compounds function as highly competitive antagonists, while $\Delta^{9}$-THC acts to generate a state of euphoria, CBD acts to block and inhibit the sense of humor (Matos et al., 2017; Lopes, 2014).

The isolation of the CBD occurred in 1940, however, it was only in 1963 that its chemical structure was elucidated (Matos et al., 2017; Gontijo et al., 2016). Research has reported that CBD has no psychoactive effects and has a broad spectrum of pharmacological action (Santos et al., 2019).

\section{CBD and the endocannabinoid system}

CBD acts on several neuronal systems and on the endocannabinoid system (Santos et al., 2019). The mechanism of action of cannabinoids was elucidated with the discovery of two endocannabinoid receptors called cannabinoid receptor type 1 (CB1) and cannabinoid receptor type 2 (CB2), corroborated by the isolation of the two endogenous ligands 2arachidonoylglycerol (2-AG) and naraquidonoil-etanolamida (AEA). Therefore, the interaction of endogenous ligands and endocannabinoid receptors is responsible for the pharmacological effects of cannabinoids (Matos et al., 2017; Gontijo et al., 2016).

CB1 are widely distributed in the body and are found mainly in the central nervous system, in presynaptic terminals, in areas linked to motor control, learning, memory, cognition and emotion, in addition to being responsible for most of the psychotropic effects of cannabinoids. CB2 are located mainly in the immune system and in specific areas of the central nervous system, such as microglia and in the postsynaptic region. They may be associated with regulation of the release of cytokines from immune cells and their migration, attenuating inflammation and pain perception / modulation (Matos et al., 2017; de Faria et al, 2020; Santos et al., 2019).

The endogenous ligands of CB1 and CB2 are called endocannabinoids and play an important role in the modulation of neurotransmission, especially as retrograde transmitters in most physiological processes, including pain, cognition, and regulation of the endocrine system, metabolic function, emotional response and motivational processes (Matos et al., 2017).

Endocannabinoids interfere with the transfer of information from pre- and post- synaptic terminals as retrograde synaptic messengers, acting as atypical neurotransmitters as opposed to classic neurotransmitters. The action ends with the capture of endocannabinoids in the presynaptic terminals. Its activation promotes the alteration of several neurotransmitters, including acetylcholine, dopamine, gamma-aminobutyric acid (GABA), glutamate, serotonin, noradrenaline and endogenous opioids, under normal physiological conditions. The discovery of the endocannabinoid system has provided new insights into a neuro- modulating scheme that may provide better treatment options for a wide variety of neurological disorders (Matos et al., 2017).

Cannabidiol, in turn, can facilitate the signaling of endocannabinoids by blocking the reuptake or enzymatic hydrolysis of AEA. However, it has low affinity for CB1 and CB2 (Matos et al., 2017).

\section{CBD and its pharmacological properties}

CBD has become the target of several experimental studies, revealing a wide spectrum of pharmacological properties with antineoplastic, immunosuppressive, analgesic, hypnotic, anxiolytic, antipsychotic, anti-inflammatory, anti-epileptic, 
anticonvulsant, neuroprotective and antioxidant properties (Matos et al., 2017; de Faria et al, 2020; Santos et al., 2019; Lopes, 2014).

The main CBD pathways and mechanisms of action that justify its therapeutic potential are: its antiproliferative and pro apoptotic properties, interfering in the adhesion and invasion of these cells, by regulating the expression of the Id-1 protein, performing an anti-tumor effect; inhibitory action of NMDA-mediated excitotoxicity (Nmethyl-D- aspartate), having an antioxidant and neuroprotective effect; stimulation of vaniloid receptors (VR1) with an efficacy similar to capsaicin (VR1 agonist), desensitizing VR1 receptors and having an analgesic and anti-inflammatory effect; agonist action on 5hydroxytryptamine 1 (5-HT1A) receptors, having an effect on anxiety mediation; among others (Matos et al., 2017; Crippa et al., 2010; de Faria et al, 2020).

As for side effects, some studies have already pointed to safety in the use of CBD for therapeutic purposes, with only mild effects such as drowsiness. Thus, CBD arouses great interest in the treatment of numerous pathologies, such as Parkinson's and Alzheimer's Diseases, autism, neoplasms, epilepsy crises and chronic pain (Matos et al., 2017; de Faria et al, 2020).

Currently the only drug sold in Brazil, containing CBD is Bayer's Sativex ${ }^{\circledR}$ oral spray, composed of $56 \% \Delta^{9}$-THC and $50 \%$ CDB. It is indicated as an analgesic for adult patients with cancer in advanced stages, for the treatment of neuropathic pain and spasms in patients with multiple sclerosis. In addition, Resolution 2,113, of October 30, 2014, regulates the compassionate use of CBD as medical therapy, restricted to the treatment of epilepsy in childhood and adolescence refractory to conventional therapies (Matos et al., 2017).

\section{CBD and its therapeutic effects in medicine}

From 1990, with the discovery of specific receptors in the CNS and the isolation of an endogenous cannabinoid, AEA, studies on these substances began to emerge, in which the appearance of evidence regarding the cannabidiol effects stood out. with great clinical applicability (Silva et al., 2017).

\section{CBD in the treatment of epilepsy}

Epilepsy is the concept applied to a brain dysfunction characterized by the periodic and unpredictable occurrence of seizures that, in turn, constitute temporary changes in behavior caused by the disordered, synchronous, and rhythmic firing of several neurons. Such modifications occur due to brain changes that generate hyperexcitability and hypersynchronism of neuronal activity, manifesting in different ways, depending on the neuronal substrates involved (Matos et al., 2017).

Epilepsy is the second most frequent neurological disorder in young adults, behind migraine, affecting about 50 million people regardless of sex, age, race and color, placing it as a global health problem. According to estimates by the Ministry of Health, approximately 157,070 new cases of epilepsy are diagnosed each year in Brazil (Matos et al., 2017; Gontijo et al., 2016; Pereira et al., 2018). The constant occurrence of epileptic seizures can seriously impair the individual's quality of life, causing brain damage, especially during the development period. Therefore, the treatment of epilepsy aiming at the control of seizure crises is extremely important, because, when not properly treated, the recurrence of crises may occur at increasingly shorter intervals (Matos et al., 2017).

Currently, more than 20 drugs with anticonvulsant properties are available worldwide, all associated with several side effects, high financial cost, and with great pharmacological resistance on the part of patients, reaching approximately one third of the patients characterized as drug resistant (Matos et al., 2017; Lopes, 2014).

Given this situation, it is evident the importance of developing new drugs for the treatment of epilepsy, especially for patient's refractory to available treatments, with effective drugs that have an essential reduction in side effects, in addition to 
the possibility of modifying the natural history of the disease, avoiding possible brain damage that could be developed (Matos et al., 2017).

The first studies on the anticonvulsant effects from CBD were carried out by the Brazilian Center for Information on Psychotropic Drugs (CEBRID), at Escola Paulista de Medicina from 1975. The beneficial effects of CBD against seizures were first observed in rats and later, in patients, in addition to a single adverse effect having been reported (drowsiness) during treatment with CBD. The absence of toxicity was analyzed through blood, urine tests, analysis of electrical and brain activity (ECG and EEG), clinical and neurological tests (Matos et al., 2017; Lopes, 2014).

In the pharmacological view, the effectiveness of the initial treatment of seizures is based on reducing the excitability of neuronal tissue, increasing the inhibitory tone. The excess of neuronal activity, resulting from some chronic or acute defect in the physiological mechanisms that regulate the flow of synaptic activation, is called epileptiform neuronal activity. Endocannabinoids are produced in response to epileptiform activity, in order to activate CB1 for excitatory neurons, to contain excess neuronal activity in order to refract it (Matos et al., 2017, Santos et al., 2019; Lopes, 2014). In this context, cannabidiol (CBD) exerts its anticonvulsant function through neuroprotective mechanisms, by balancing excitation / neural inhibition (Gontijo et al., 2016).

To date, the therapeutic use of CBD is safe and effective, and it can become the first cannabinoid applied in the treatment of epilepsy (Matos et al., 2017).

\section{CBD in the treatment of autism}

Autism spectrum disorder (ASD) is a syndrome that affects the neurological system and causes, in the patient, social difficulties (with or without speech), motor planning, hypersensitivity, convulsions and aggression. This syndrome has genetic and environmental issues and can be aggravated over time, if not treated correctly (Lopes, 2014).

Currently, conventional treatments for this syndrome consist, precisely, in the control of these symptoms mentioned above, including both medication measures and psychotherapies. For this, several different drugs are used more frequently, such as antipsychotics, benzodiazepines, anxiolytics, serotonin reuptake inhibitors, psychostimulants, mood stabilizers and anticonvulsants. However, they have side effects such as: insomnia or drowsiness, binge eating or lack of appetite, aggressiveness and irritability (Lopes, 2014; Oliveira \& Pottker, 2019).

More current studies suggest the use of CBD, which even offers a broader action potential, as it does not only act on psychological and physical control (decreased aggression, insomnia, hyperactivity, among others), but also acts on several functions of the organism (Gontijo et al., 2016).

The endocannabinoid system appears outside its homeostasis in patients with ASD. In this way, it works as an agonist of the endocannabinoid system, providing homeostasis in the body, through the CB1 and CB2, adjusting the serotonin production and regulating the excess of neuronal activities, providing not only the improvement of common symptoms, but also those caused by the side effects of the most commonly used drugs (Lopes, 2014; Oliveira \& Pottker, 2019).

In addition, CBD also assists in psychotherapeutic treatment, reducing aggressive and inattentive behaviors, promoting more patient engagement in this type of therapy and favoring the inclusion of this type of work in the treatment of autism, seeking more efficiently a more comprehensive work by reducing perception, cognition and mood challenges, common in these patients (Oliveira \& Pottker, 2019).

\section{CBD in cancer treatment}

In recent years, it has been shown that CBD-based drugs can provide valuable symptom relief to cancer patients, as well as helping to fight the disease itself. Regarding the fight against the tumor, CBD exhibits pro-apoptotic and 
antiproliferative actions in different types of tumors and can have anti-migratory, anti-invasive and anti-metastatic properties, that is, CBD presents itself as a potent inhibitor of growth and spread of cancer. Interestingly, its effect against cancer appears to be selective for cancer cells as it does not affect the normal cell lines, thus demonstrating incredible efficiency, since it has capacity of achieve multiple cellular pathways that control tumorigenesis by modulating different intracellular signaling, depending on the type of cancer considered. Finally, another interesting aspect in the relationship between CBD and fighting cancer is the fact that its use in combination with chemotherapy drugs can have a synergistic effect, where they work together to potentially reduce the required chemotherapy dose, thereby reducing the toxicity, but maintaining the effectiveness of the drugs (Massi et al., 2013).

In addition to acting to combat the development of cancer, CBD is also very important in mitigating the side effects resulting from the disease itself and its treatment. One of the main debilitating side effects of cancer is the pain it causes. The pain is often caused by the tumor itself, which puts pressure on the nerves, bones and organs of the body. Chemotherapy medications also cause pain as a side effect, often with tingling and numbness in the fingers and toes. CBD has significant effectiveness in relieving chronic pain, including neuropathic pain, in addition to having no side effects. Thus, CBD can be an important tool in the control of pain in cancer patients, at least as an adjunct to current medications (Casey \& Vaughan, 2018; Johnson et al., 2010).

Another important side effect of cancer treatment is reduced appetite. A healthy appetite is vitally important to supply the body with the necessary nutrients to promote healing. Some studies have shown that CBD increases chemosensory perception. This not only makes food taste better, but it also increases your calorie intake via protein and your overall appetite through CBD. Nausea and vomiting are common side effects of chemotherapy. Treatment of these symptoms will offer a significant improvement in the overall quality of life of cancer patients. Cannabis has been used for centuries to alleviate much as nausea vomiting. There is evidence to support the use of CBD for therapeutic improvement in chemotherapy-induced nausea and vomiting (Abrams, 2018).

Another issue in which CBD can play an important role is in helping to combat anxiety and depression that affect many patients who face a disease so difficult to deal with. Thus, reducing anxiety and depression greatly helps the body to fight and recover. CBD has well-known calming effects and has demonstrated therapeutic potential for a wide range of psychiatric disorders, such as mood disorders, anxiety, depression and bipolar disorder. By exerting anxiolytic effects, small doses already improve mood and increase serotonin levels in the brain (Giacoppo et al., 2014).

Finally, CBD can also improve the quality of the patient's sleep, because by decreasing the feeling of pain and anxiety, the patient is able to have a better night's sleep.

Thus, the relevance of CBD in oncological treatment is undeniable, and the realization of more and more studies on this topic is significant.

\section{CBD in the treatment of chronic pain}

Chronic pain includes a wide variety of clinical conditions and is the most common symptom that leads patients to seek medical attention (Ascenção et al., 2016).

In the last decade, scientific research has advanced in search of determining the effects of cannabinoids on nociceptive neurotransmission. These investigations made it possible to better understand the basic mechanisms and to develop pharmacological alternatives with more specific effects. Researchers demonstrated increased expression of CB1 in the contralateral thalamus after a neuropathic pain model, which could explain the greater analgesic efficacy of cannabinoids in chronic cases. The activation of CB1 is associated with the anti-hyperalgesic and antiallodynamic properties of cannabinoids. 
CB1, the receptor most related to pain pathways, when activated, blocks pain transmission routes through voltage-dependent channels (Bonfá et al., 2008).

CB2 classically related to the immune response, are implicated with antinociception. When low doses of cannabinoids and subtherapeutic doses of morphine are administered, there is an important potentiation of the nociceptive effect due to the synergistic action of the two substances. Concomitant administration improves the effectiveness and safety of pain control, especially since cannabinoids do not produce respiratory depression (Ascenção et al., 2016; Bonfá et al., 2008).

Cannabinoids are a tool in the management of patients with chronic pain and can reduce pain scales by up to $30 \%$. Its reported effects are: decreased pain, increased pain tolerance, improved quality of life, return to activities of daily living. However, until now, no curative effect of pain has been reported. The main studies on pain are: chronic neuropathic pain of any etiology; fibromyalgia; pain in multiple sclerosis; pain in spinal cord injury; cancer pain and as an adjunct to improved mood and sleep. It is not recommended for acute, episodic or post-surgical pain (Ascenção et al., 2016; Bonfá et al., 2008).

The use of cannabinoids has been shown to have a beneficial effect and is indicated as a third line of treatment for patients with severe neuropathic pain, which interferes with their daily functions, as well as for those with low response to the use of conventional treatments, with first and second drugs. treatment lines, or that have low tolerability to their side effects (Ascenção et al., 2016.

\section{CBD in the treatment of Parkinson's disease (PD)}

Parkinson's disease (PD) is a chronic neurodegenerative disorder with an incidence of 1 to $2 \%$ in the world population over 65 years, and with an estimated prevalence of 3.3\% in Brazil, being characterized by motorestypical symptoms such as bradykinesia, tremors and stiffness, in addition to neuropsychiatric symptoms such as psychotic, mood, sleep and anxiety disorders. PD is caused by the degeneration of neurons that produce the neurotransmitter dopamine in a brain region called the basal ganglia, specifically in the region called the substantia nigra, which results in a reduction in the amount of dopamine in another brain area, the striatum (de Faria et al, 2020; dos Santos et al., 2019).

Currently, pharmacological treatment for PD patients basically involves the administration of dopamine precursors such as levodopa (L-DOPA). However, in a significant proportion of patients, these medications decrease their therapeutic effect over time, producing serious adverse reactions (dos Santos et al., 2019).

Studies carried out in animals and humans demonstrate that the endocannabinoid system undergoes neurochemical changes during the evolution of $\mathrm{PD}$, suggesting a possible therapeutic use of $\mathrm{CBD}$ in the treatment of this disease. Cannabinoid receptors (CB1 and CB2), as well as endocannabinoid compounds (AEA and 2-AG) are found in large concentrations in brain areas involved in the processing and execution of body movements, such as the basal ganglia (de Faria et al, 2020; dos Santos et al., 2019).

The antiparkinsonian effects of cannabinoids could be produced by their antioxidant, anti-excitotoxic, antiinflammatory, neuroprotective and anxiolytic properties (de Faria et al, 2020; Santos et al., 2019; Gontijo et al., 2016; Pereira et al., 2018). Research conducted with patients who used CBD for the treatment of PD reported improvements in general symptoms, bradykinesia, muscle stiffness, tremors and dyskinesia, in addition to improvements in mood, sleep and psychotic symptoms (Gontijo et al., 2016; dos Santos et al., 2019). Concomitant to this, there was an improvement in the total scores of the Unified Parkinson's Disease Rating Scale - used to assess the evolution of PD in patients - and the Parkison's Disease Questionnaire - used to report health status and quality of life of PD patients (de Faria et al, 2020).

Furthermore, CBD reduced the scores for global PD symptoms and did not produce motor effects, adverse effects and worsens our cognitive symptoms (Gontijo et al., 2016; dos Santos et al., 2019). In this scenario, interest in the study of the 
endocannabinoid system has grown, verifying the effect of CBD which has been presented as a therapeutic alternative, with a broad spectrum of action, including anxiolytic, as well as an option with fewer side effects (de Faria et al, 2020).

\section{CBD in the treatment of Alzheimer's disease (AD)}

Alzheimer's disease, responsible for $50 \%$ to $80 \%$ of brain disease cases, is the main cause of dementia in the world and causes problems that affect memory, thinking and behavior (Silva et al., 2019). Its clinical and neuropathological characteristics were described by the neurologist German, Alois Alzheimer, in 1907. The nuerological damages caused by Alzheimer's disease are still considered irreversible and the patient's prognosis is, generally, 5 to 10 years, a period in which he presents gradual loss of memory and other cognitive functions (Gontijo et al., 2016).

$\mathrm{AD}$ has a higher incidence in individuals over the age of 65 , being caused by the abnormal accumulation of certain proteins in brain tissue that leads to the death of neurons, resulting in the formation of extracellular senile plaques and intracellular neurofibrillary tangles in neuronal cells (Gontijo et al., 2016).

There are currently only four drugs approved for the treatment of Alzheimer's disease, they are: donezepil, rivastigmine, galantamine and memantine. These drugs can have adverse effects such as abdominal pain, anorexia, dizziness, nausea, vomiting, diarrhea, headache and insomnia (Gontijo et al., 2016).

In view of this situation, the development of treatment methods to delay or halt the progression of the disease became necessary, aiming to reduce the costs associated with the treatment of the disease and improve the quality of life of patients, looking for new substances and more effective drugs and less aggressive to the patient's body (dos Santos et al., 2019; Silva et al., 2019).

Cannabidiol reduces the accumulation of $\beta$-amyloid plaques, demonstrating the great potential of cannabis to treat diseases. CBD has the ability to control microglial and neuroinflammatory function by combining its anti-inflammatory and antioxidant effects, making it beneficial for the survival rate of cells (Silva et al., 2019). The use of CBD as therapy is gaining more and more strength, and it is increasingly likely to be included in the therapeutic arsenal, but the therapeutic properties of CBD need to be further studied to expand the understanding of the substance, determine its therapeutic window, and to better understand its mechanism of action in the treatment of neurological diseases. So that patients and prescribers are offered greater security in the management of medications (dos Santos et al., 2019).

\section{CBD in the treatment of gastrointestinal disorders}

Cannabis has gained significant attention in alternative treatment for gastrointestinal disorders in recent years. Studies have identified a new layer of regulation of the function of neutrophils in the intestine, which function as a warning system, in the form of chemo- attractants, for immune cells to act on intestinal epithelial cells, regulating the pro- inflammatory balance (Szabady et al., 2018).

The migration of neutrophils through the intestinal epithelium (from the submucosal compartment to the epithelial lumen), allows them to get involved with the pathogens before coming into contact with the host. In addition, studies have shown that CB2 ligands present in the intestine reduce the intensity of inflammatory cell migration to the intestinal epithelium and, consequently, the symptomatic manifestations of the inflammatory mechanism in patients (Szabady et al., 2018).

Thus, the use of cannabidiol can be very promising in the treatment of irritable bowel syndromes (IBS), characterized by a set of intestinal manifestations that may or may not be linked to a specific cause. Patients with a diarrhea for IBS have overactive activity in the gastrointestinal tract, that is, the digestion and absorption of the food eaten does not occur properly, leading to a series of symptoms, such as cramps, abdominal pain, bloating, nausea and diarrhea. CBD is shown as an alternative to control this syndrome, since it reduces the intestinal muscle activity, aiding in the digestion of these foods, and 
consequently slower absorption of nutrients, regulating the entire digestive process of the gastrointestinal tract (Couch et al., 2017).

In the most severe cases of IBS, patients have low activity of the gastrointestinal tract, that is, there is a reduction in enzyme production, mainly of pancreatic enzymes, and consequently, a failure in the digestion of the food eaten, both due to the enzymatic deficiency and the difficulty of peristalsis in move the bolus along the gastrointestinal tract, then leading to constipation. CBD, in this case, helps in the natural release of an endocannabinoid, AEA, responsible for delaying the movement of the intestine, facilitating the digestive process and peristalsis, fighting inflammation and controlling the diversity of the microbiota (Couch et al., 2017).

\section{Final Considerations}

CBD can be recommended for numerous diagnoses and symptoms, considerably improving severe conditions and often already resistant to conventional treatments. Health and patient care can be offered at home, hospitals and specialized institutions, aiming to improve the quality of life through the prevention or mitigation of disease symptoms. Thus, there is an enormous facility in making the treatment with the phytotherapic plant, since it does not require care that leads to high costs with sophisticated equipment, only careful cultivation. In addition, CBD is a very promising molecule with regard to the treatment of neurodegenerative diseases. The data presented in this review demonstrate that cannabinoids may, in the future, be an important therapeutic option in the treatment of Parkinson's and Alzheimer's diseases, epilepsy, autism, neoplasms and still acting in the relief of pain. This is due to the absence of psychoactive effects and cognition, safety, good tolerability, clinical trials with positive results and the wide spectrum of pharmacological actions. However, even considering all the promising aspects of the molecule, there is a need to reinforce these studies, in order to better understand its mechanisms of action, its pharmacokinetics, pharmacodynamics and especially the possible side effects of using this compound. Likewise, due to the fact that the CBD's actions are biphasic, that is, several effects depending on the doses administered, which further increases the need to carry out more in-depth and detailed studies of the different actions of the CBD.

\section{References}

Abrams, D. I. (2018). The therapeutic effects of Cannabis and cannabinoids: an update from the National Academies of Sciences, Engineering and Medicine report. European Journal of Internal Medicine, 49, 7-11. https://doi.org/10.1016/j.ejim.2018.01.003

Ascenção, M. D., Lustosa, V. R. \& da Silva, L (2016). J. Cannabinoids in the treatment of chronic pain. Rev Med Saude Brasilia, 5 (3), 255-63

Bonfá, L., Vinagre, R. C. O. \& Figueiredo, N. V. (2008). Cannabinoid use in chronic pain and palliative care. Rev. Bras. Anestesiol, 58(3). https://doi.org/10.1590/S0034-70942008000300010

Casey, S. \& Vaughan, C. W. (2018). Plant-Based Cannabinoids for the Treatment of Chronic Neuropathic Pain. Medicines, 5(3), 67. https://doi.org/10.3390/medicines5030067

Couch, D.G.. Tasker, C.. Theophilidou, E. et al (2017). Cannabidiol and palmitoylethanolamide are anti-inflammatory in the acutely inflamed human colon. Clin Sci, 131(21), 2611-2626. https://doi.org/10.1042/CS20171288.

Crippa, J. A. S.. Zuardi, A. W.. \& Hallak, J. E. C. (2010). Therapeutic use of cannabinoids in psychiatry. Rev. Bras. Psychiatrist, 32(1). https://doi.org/10.1590/S1516- 44462010000500009

de Faria, S. M.. Fabricio, D. M.. Tumas, V. et al (2020). Effects of acute administration of Cannabidiol on anxiety and tremors induced by the public speaking simulation test in patients with Parkinson's disease. J Psychopharmacol, 34(2), 189-196. http://doi: 10.1177/0269881119895536

dos Santos, R. G.. Hallak, J. E. C.. \& Crippa1, J. A. S. (2018). The use of cannabidiol (CBD) in the treatment of Parkinson's disease and its comorbidities. Rev Med, 98(1), 46-51. https://doi.org/10.11606/issn.1679-9836.v98i1p46-51

Giacoppo, S.. Mandolino, G.. Galuppo, M. et. al. (2014). Cannabinoids: New promising agents in the treatment of neurological diseases. Molecules, 19(11), 18781-18816, https://doi.org/10.3390/molecules191118781

Gontijo, E. C.. Castro, G. L. Petito, A. D. C. et. al (2016). Cannabidiol and its therapeutic applications. Refacer, 5(1). https://doi.org/10.36607/refacer.v5i1.3360 
Research, Society and Development, v. 10, n. 14, e452101422239, 2021

(CC BY 4.0) | ISSN 2525-3409 | DOI: http://dx.doi.org/10.33448/rsd-v10i14.22239

Johnson, J. R.. Burnell-Nugent, M.. Lossignol, D. et. al. (2010). Multicenter, Double-Blind, Randomized, Placebo Controlled, Parallel-Group Study of the Efficacy, Safety, and Tolerability of THC: CBD Extract and THC Extract in Patients with Intractable Cancer-Related Pain. Journal of Pain and Symptom Management, 39 (2), 167-179. https://doi.org/10.1016/j.jpainsymman.2009.06.008

Lopes, R. M. (2014).Canabinoides help to uncover common etiological aspects and bring hope for the treatment of autism and epilepsy. Revista da Biologia, 13(1), 43-59. https://doi.org/10.7594/revbio.13.01.07

Matos, R. L. A.. Spinola, L. A.. Barboza, L. L. et al (2017). The Use of Cannabidiol in the Treatment of Epilepsy. Rev. Virtual Quim., 9 (2), $786-814$. https://doi.org/10.21577/1984- 6835.20170049

Massi, P.. Solinas, M.. Cinquina, V. et. al. (2013). Cannabidiol as potential anticancer drug. British Journal of Clinical Pharmacology, 75(2), 303-312. https://doi.org/10.1111/j.1365- 2125.2012.04298.x.

Oliveira, A. D. C. \& Pottker, C. A. (2019). Considerations about Canabidiol in the psychotherapeutic process of children with autistic spectrum disorder. Rev. UNINGÁ Review, 34(4), 24-37. https://doi.org/10.46311/2178-2571.34.4.024-037

Pereira, F. A.. Torres, A. C.. Philadelpho, V. O. et. al (2018). Effects of Canabidiol on the frequency of epileptic crisis: a systematic review. Brazilian Journal of Neurology and Psychiatry, 22(1), 86-100

Santos, A. B.. Scherf, J.. \& Mendes, R. C. (2019). Efficacy of cannabidiol in the treatment of seizures and diseases of the central nervous system: systematic review. Acta Brasiliensis, 3(1), 30-34. http://doi.org/10.22571/10.22571/2526-4338131

Silva, D. O. F.. Reis, M. C.. Santos, B. E. M. et al (2017). The Use of Cannabidiol in the Treatment of Anxiety. Rev Med Saude Brasilia. 6(2), 255-60.

Silva, R. C., et. Al (2019). Use of Canabidiol in the treatment and prevention of Alzheimer's evil: scientific and technological prospection. ISTI/SIMTEC, 10(1), 912-921. https://doi.org/10.7198/S2318-3403201900010937

Szabady, R. L.. Louissaint, C.. Lubben, A. et al (2018). Intestinal P-glycoprotein exports endocannabinoids to prevent inflammation and maintain homeostasis. J Clin Invest, 128(9):4044-4056. https://doi.org/10.1172/JCI96817. 